\title{
PREVALENCE OF PSYCHIATRIC DISORDERS IN MALE ADOLESCENTS IN URBAN AREAS IN EGYPT
}

\author{
By \\ Mohammed Mohammed Abdel-Khalik Eldeeb
}

\author{
Department of Psychiatry, Faculty of Medicine, Al-Azhar University \\ Deeb17777@gmail.com
}

\begin{abstract}
Background: Knowledge about the epidemiology of mental disorders in children and adolescents is essential for research and planning of health services. Surveys can provide prevalence rates, whereas population-based registers are instrumental to obtain precise estimates of incidence rates and risks.

Objective: To study the morbidity and the outbreak rate of the psychiatric illnesses among adolescents in Egyptian urban areas.

Patients and Methods: This study was conducted during the period from December 2017 to April 2018, this study was conducted on 1014 students: 500 students from Khalil Agha school and 514 from Ismail Al-Kabbany school in Cairo, Egypt. All participants were subjected to Socioeconomic standard application, General health questionnaire (GHQ), Semi-structured clinical interview according to DSM5, Eysenck personality questionnaire for those given positive results by GHQ and Investigations included CT brain and EEG, as per the clinical interview, in order to exclude organic cases.

Results: The sample age was 12-19 years and averaged at (14.99), with a standard deviation of (1.53). The number of those who had psychiatric disorders was(154) and $(15.2 \%)$, while the number of those who didn't have any psychiatric disorders was 860 and $(84.8 \%)$, Anxiety disorders were the most common in the sample with a percentage of (6.8\%), including Generalized Anxiety Disorder (GAD) (2.2\%), Social Phobia (2.1\%), Obsessive Compulsive Disorder (OCD)(0.8\%), Specific Phobia (0.7\%), Panic Disorder $(0.7 \%)$, Single Panic Attack (0.2\%), Anxiety Disorder Not Otherwise Specified $(0.2 \%)$, Depressive Disorders (4.9\%), which included Major Depression (2.2\%), Minor Depression (1.7\%), Dysthymia (1.3\%); Adjustment Disorders (2.4\%), Conduct Disorder (0.4\%), Nightmares Disorder $(0.2 \%)$ and Teeth-Grinding Disorder $(0.2 \%)$, The GHQ results average value were $28.68 \%$, with a standard deviation of (12.87). Positive results reached $(91.3 \%)$, while negative ones reached $(8.7 \%)$. There was an indicative increase in the GHQ results average value among the ill group, compared to the normal one, The Average value of the socioeconomic standard results was $(65.14 \%)$, with a standard deviation of (16.88), The results average of Eysenck personality questionnaire hit (46.47), with a standard deviation of (6.26). The average results of the branch scales were: Lie: (14.7), with a standard deviation of (14.4), Neurosis: (13.65), with a standard deviation of (4.5), Extroversion: (12.24), with a standard deviation of (3.12), Psychosis: (5.8), with a standard deviation of (3.21).
\end{abstract}

Conclusion: Rate of psychiatric disorders increased in Egyptian male adolescents in urban areas.

Key words: Psychiatric disorders, Male adolescents, Urban areas. 


\section{Mohammed Mohammed Abdel-Khalik Eldeeb}

\section{INTRODUCTION}

Since 1990, studies on the global burden of disease have continuously ranked mental disorders as some of the most impairing conditions worldwide (Whiteford et al., 2013), The Global Burden of Disease studies reported that, in children and adolescents, mental disorders account for the most years lived with disability ( Institute for Health Metrics and Evaluation,(2018).The World Health Organization emphasized in their Mental Health Action Plan 2013-2020 the strong need for age- and sex-specific data on child mental health.( Nielsen et al., 2016). The United States and Australia have good survey data, but only $7 \%$ of all countries worldwide have such data (Erskine et al., 2017). In 2013, none of 29 member states in the European Union could provide data on incidence of mental disorders in children or adolescents (Elsabbagh et al., 2012). Knowledge of the age-specific risks of mental disorders forms the backbone for public health decisions, prioritization of resources, evidence-based medicine, and research on risk factors and outcomes. Occurrence of a condition in a population is measured as prevalence (cases at a specific point) or incidence (new cases per unit of time). The cumulative incidence estimates the risk of developing the condition before a specified age, taking into consideration individual follow-up time (Rothman et al., 2011). Estimates of the prevalence of mental health disorders in childhood are often based on information from adolescents or parents and are thus prone to recall, information, and survival biases. In adults, health registry data have made important contributions to our understanding of the incidence of the full spectrum of mental disorders (Pedersen et al., 2014) and their risk factors and outcomes (McGrath et al., 2014) In children and adolescents, similar methods have been informative about the frequency of a few certain mental disorders (Atladóttir et al 2012) and their comorbidities, risk factors (Nielsen et al., 2016) and outcomes. These findings have been supplemented by prevalence estimates from surveys, most often at a single point (Elsabbagh et al., 2012) and sometimes with repeated assessments.

The present work aimed to study the morbidity and the outbreak rate of the psychiatric illnesses among male adolescents in Egyptian urban areas.

\section{PATIENTS AND METHODS}

This was an epidemiological study conducted on 1014 student: 500 students from Khalil Agha school, and 514 from Ismail Al-Kabbany school in Cairo, Egypt. The schools were chosen randomly, and all participants after approval to share in study were subjected to Socioeconomic standard application, and Generalized health questionnaire (GHQ). Semi-structured clinical interview was done according to DSM 5 and Eysenck personality questionnaire for those given positive results in GHQ. Investigations included $\mathrm{CT}$ brain and EEG, as per the clinical interview, were done in order to exclude organic cases, and the study was done during the period from December 2017 to April 2018.

Statistical analysis: Two types of statistics were done:

1-Descriptive statistics

Quantitative data were shown as mean, $\mathrm{SD}$, and range.

Qualitative data was expressed as frequency and percentage.

2-Analytical statistics: Mann Whitney test was used to compare mean and SD of 2 sets of quantitative when their data were not normally distributed, $P$ value was considered statistically significant when $\mathrm{p}$ $\leq 0.05$. 


\section{RESULTS}

Oure studied group was $84.8 \%$ normal and $15.2 \%$ diseased (Table1).

Table (1): Prevalence of psychiatric illness among the studied group:

\begin{tabular}{|l||lc||}
\hline & No. & $\%$ \\
\hline \hline Normal: & 860 & 84.8 \\
Diseased: & 154 & 15.2 \\
\hline
\end{tabular}

Our studied group was $84.8 \%$ normal, panic disorder $0.7 \%$, panic attacks $0.2 \%$, General anxiety disorders $2.2 \%$, Anxiety disorders not otherwise specified Obsessive Compulsive - disorders $0.8 \%, \quad 0.2 \%$ and conduct disorder $0.4 \%$ (Table Specific phobia $0.7 \%$, social phobia $2.1 \%$, 2).

Table (2): Percentage distribution of the results of the interview (clinical diagnosis) among the studied group $(n=1014)$

\begin{tabular}{|l||lc||}
\hline Interview: & No. & $\%$ \\
\hline \hline Normal: & 860 & 84.8 \\
General anxiety disorders: & 22 & 2.2 \\
Obsessive Comp. disorders: & 8 & 0.8 \\
specific phobia: & 7 & 0.7 \\
Social phobia: & 21 & 2.1 \\
Panic disorders: & 7 & 0.7 \\
Panic attacks: & 2 & 0.2 \\
Anxiety disorders not otherwise specified: & 2 & 0.2 \\
Anxiety disorders: & 69 & 6.8 \\
Minor depression: & 17 & 1.7 \\
Major depression: & 20 & 2.0 \\
Dysthymia: & 13 & 1.3 \\
Depression disorders: & 50 & 4.9 \\
Stuttering: & 3 & 0.3 \\
Night mares: & 2 & 0.2 \\
Adjustment disorders: & 24 & 2.4 \\
Teeth grinding: & 2 & 0.2 \\
Conduct disorders: & 4 & 0.4 \\
& & \\
\hline \hline
\end{tabular}


Our studied group was $91.3 \%$ positive on GHQ and $8.7 \%$ negative (Table 3).

Table (3): Percentage distribution of the results of GHQ score among the studied group.

\begin{tabular}{|l||lc||}
\hline GHQ score & No. & $\%$ \\
\hline \hline Negative: & 88 & 8.7 \\
Positive: & 926 & 91.3 \\
\hline
\end{tabular}

Mean value of our studied group was 28.68 and 65.14 for GHQ and Socioeconomic standard respectively (Table4).

Table (4): Mean values of GHQ and Socioeconomic standard (SES)score among the studied group.

\begin{tabular}{|l||l|}
\hline & Mean \pm SD \\
\hline \hline GHQ & $28.68 \pm 12.87$ \\
\hline Socioeconomic standard & $65.14 \pm 16.88$ \\
\hline
\end{tabular}

Mean values of Our studied group on Eysenck questionnaire were Eysenck psychotic $5.85 \%$, Eysenck extroversion
12.245, Eysenck lying 14.7\%, Eysenck neurotic $13.65 \%$ and Eysenck total $46.47 \%$ (Table 5).

Table (5): Mean values of Eysenck score among the studied group.

\begin{tabular}{|l||l||}
\hline Eysenck score: & Mean \pm SD \\
\hline \hline Eysenck psychotic: & $5.85 \pm 3.21$ \\
\hline Eysenck extroversion: & $12.24 \pm 3.12$ \\
\hline Eysenck lying: & $14.70 \pm 4.14$ \\
\hline Eysenck neurotic: & $13.65 \pm 4.50$ \\
\hline Eysenck total score: & $46.47 \pm 6.26$ \\
\hline
\end{tabular}


Our studied group had differences between normal and diseased group with statistical significance regarding GHQ and
Eysenck statistical questionnaires while no regarding socioeconomic standard scale (Table 6).

Table (6): Comparison between normal and diseased groups regarding the results of GHQ, SES and Eysenck scores as risk factors used Mann-Whitney test

This table shows that the mean GHQ score, SES score, Eysenck psychotic, Eysenck lying, Eysenck neurotic and Eysenck total score were significantly higher among the diseased group.

\begin{tabular}{||l||l|l||l||}
\hline \hline $\begin{array}{l}\text { Groups } \\
\text { Parameters }\end{array}$ & $\begin{array}{l}\text { Normal }(\mathrm{n}=860) \\
\text { Mean } \pm \text { SD }\end{array}$ & $\begin{array}{l}\text { Diseased }(\mathrm{n}=154) \\
\text { Mean } \pm \mathrm{SD}\end{array}$ & P value \\
\hline \hline GHQ score & $27.89 \pm 12.72$ & $33.10 \pm 12.82$ & 0.000 \\
\hline SES score & $64.64 \pm 16.89$ & $67.94 \pm 16.60$ & 0.02 \\
\hline Eysenck psychotic & $5.74 \pm 3.14$ & $6.46 \pm 3.51$ & 0.03 \\
\hline Eysenck extroversion & $12.20 \pm 3.07$ & $12.46 \pm 3.33$ & 0.34 \\
\hline Eysenck lying & $14.57 \pm 3.99$ & $15.37 \pm 4.79$ & 0.03 \\
\hline Eysenck neurotic & $13.16 \pm 4.49$ & $16.13 \pm 3.62$ & 0.000 \\
\hline Eysenck total & $45.70 \pm 6.06$ & $50.41 \pm 5.81$ & $<0.001$ \\
\hline
\end{tabular}

\section{DISCUSSION}

The mean age in the sample was 14.99 years, with a standard deviation of 1.53 .

The average value of GHQ results in the sample was 28.68 , with a standard deviation of 12.87 , and the percentage of positive results for this questionnaire in the sample was $91.3 \%$, while the percentage of negative results was $8.7 \%$ and there was a statistically significant increase in the percentage of positive public health questionnaire values in the diseased group than in the healthy group. This was supported by study of Rothman et al., (2011), who found that the percentage of positive results for GHQ $88 \%$ while the percentage of negative results was $12 \%$.

The mean of the results of the total score of the Eysenck questionnaire for personality in this sample was 46.47 with a standard deviation of 6.26 , and the mean scores of the sub-scales of this questionnaire were the average lie score was 14.70 with a standard deviation 4.14 , The average degree of neuroticism was 13.65 with a standard deviation 4.50 , the mean diastolic score was 12.24 with a standard deviation of 3.12 , the mean score for psychosis was 5.8, with a standard deviation of 3.21. Perhaps these results were due to students' inability to understand the questions sufficiently and their attempt to lie in order not to appear badly in front of the interrogator and in front of their colleagues, which led to high rates of lying in this sample, this was supported by study of Elsabbagh et al., (2012).

Anxiety disorders were the most prevalent in the sample followed by depressive disorders, adjustment disorder, conduct disorder, stuttering disorder, nightmares disorder and sleep grinding disorder. Prevalence of major depression was at a rate of $2.2 \%$, minor depression was at a rate of $1.7 \%$, dysthymia was at a rate of $1.3 \%$, and all depressive disorders 


\section{Mohammed Mohammed Abdel-Khalik Eldeeb}

were at a rate of $4.9 \%$. This result was consistent with the study of Sarkar et al. (2012) who found the prevalence of depressive disorders in the sample was $3.13 \%$, while the prevalence of depressive disorders decreased in the study of Pillai et al., (2018) who found that the percentage of psychiatric disorders in the sample was $1.81 \%$ and anxiety disorders were the most prevalent by rate of $1 \%$, followed by depressive disorders with a rate of $0.5 \%$. The percentage was also higher in the study of McGrath et al., (2014) who found the prevalence of depressive disorder was $34 \%$. He used the Beck self-administered standard questionnaire. While the percentage differed in study of Dubovsky (2012), who based on personal interviews and psychological questionnaires found that the prevalence of mental disorders in adolescents was $40 \%$ during the year prior to conducting the study and $23 \%$ during the month preceding the study, The prevalence rate was $10 \%$ during the year previous to the study where The prevalence rate of dysthymia in the sample was $1.3 \%$ and this result was close to study of Peter et al., (2013) who found the prevalence of dysthymia and bipolar disorder in the sample at a rate of less than $1 \%$ while the prevalence of major depressive disorder in participants with More prior history of major depression than participants with a prior history of non-affective disorders and participants without a prior history of mental illness, prevalence rates of post -traumatic stress disorder among these participants in early adulthood were $9 \%, 5.6 \%$ and $3.7 \%$ respectively.The overall prevalence of anxiety disorders in our study was (6.8\%), obsessive-compulsive disorder was $0.8 \%$, generalized anxiety disorder $2.2 \%$, specific phobic disorder $0.7 \%$, social phobia disorder $2.1 \%$, panic disorder $0.7 \%$ and single panic attack
$0.2 \%$.this was supported by study of Merikangas and Kessler (2010) who found that $8 \%$ of the adolescents in the sample suffered from serious emotional disturbances and anxiety disorders were the most prevalent, while the rate of anxiety disorders decreased to $1 \%$ in the study of Pillai et al., (2018). The prevalence of these disorders increased in study of Dubowski (2012), who found the prevalence of mental disorders in adolescents was $40 \%$ during the year Previous to conducting the study and $23 \%$ during the month prior to the study while the rate of anxiety disorders decreased to $1 \%$ in the study of Pillai et al. (2018).

Prevalence of obsessivecompulsive disorder in this sample was $0.8 \%$, This percentage was close to the results of the study of Sultan and AbelRahman (2012) in which the prevalence of obsessive-compulsive disorder was $1.2 \%$. Also, study of Abay et al., (2010) who found that the prevalence of obsessivecompulsive disorder in the sample was $1.4 \%$, while this percentage increased in study of Abdellatif (2013) who found the percentage of obsessive-compulsive disorder in the sample was $2.7 \%$ and study of Assarian et al. (2016) who found the prevalence of obsessive-compulsive disorder in the sample was $8.87 \%$.

Prevalence of generalized anxiety disorder in this sample was $0.7 \%$. This result was consistent with the study of Merikangas et al., (2010) who found that the spread of generalized anxiety disorder in the sample was at a rate of $0.7 \%$, while this result does not agree with study of Wittchen (2012) and study of Keeton et al., (2019) who found the prevalence of generalized anxiety disorder in children and adolescents was $10 \%$.

The prevalence rate of specific phobia in this sample was $0.7 \%$. This differed from study of Kim et al. (2010) in which the rate of specific phobia was 
$7.9 \%$ and study of Dubovsky (2012) in which the prevalence of specific phobia was $16 \%$.

The prevalence rate of social phobia in this sample was $2.1 \%$. This result was close to the study of Cecilia et al., (2013) in which the prevalence of social phobia was $1.6 \%$, while this result differed from study of Dubovsky (2012) in which the prevalence of this disorder was $8 \%$.

The prevalence of panic disorder in this sample was $0.7 \%$ and the prevalence of a single panic attack was $0.2 \%$. These results were consistent with study of Merikangas et al., (2010) in which the prevalence of panic disorder was $0.7 \%$ and study of Diler (2013) in which the prevalence of panic disorder was $0.5-5 \%$ in general population, and its prevalence in adolescents was at a rate of $0.2-10 \%$. This result differed from the result of Biederman et al., (2017) who found the prevalence of panic disorder $6 \%$ and rate of space phobia disorder $10 \%$.

The prevalence rate of adjustment disorder in the sample was $2.4 \%$, while in the study of Bird et al. (2011) it was $4.2 \%$. The rate of conduct disorder was $0.4 \%$. These results differed from study of Merikangas et al. (2010) who found that the prevalence of conduct disorder in the sample was at a rate of $2.1 \%$, and study of Sujit et al., (2016) who found the prevalence of conduct disorder was $4.58 \%$.

The prevalence rate of stuttering disorder in the sample was $0.3 \%$. This result was consistent with study of David (2017) who found that the prevalence rate of stuttering disorder was $0.33 \%$, voice disorder was $0.12 \%$ and speech-sound disorder was $1.06 \%$, while this result differed from the result of Hans (2010) who found that the incidence of stuttering disorder in early childhood was $5.19 \%$.
The prevalence rate of teeth Grinding disorder during sleep was $0.2 \%$. This result differed from the result of the study of Strusz et al. (2010) who found the rate of teeth grinding disorder during sleep was $13.7 \%-21.7 \%$.

The prevalence rate of nightmares disorder was $0.2 \%$. This result differed from the study of Munezawa et al.,(2011) who found that the prevalence of nightmares disorder and Sleep Paralysis disorder were at a rate of $35.2 \%$ and $8.3 \%$ respectively.

Medical investigations were conducted on cases suspected to have organic disorders such as those had chronic headache or involuntary movements. The results were $0.3 \%$ of the sample had Sinusitis and $0.2 \%$ had Epilepsy, and none of them had psychiatric disorder, and these results did not affect results of the study as they have been excluded from the study. The difference in results between different studies may be due to the difference in psychological scales and questionnaires used in different studies, the different methods of sample selection in different studies, the age difference of the subjects in the different studies, and the difference in economic and social level of the individuals examined in the different samples.

\section{CONCLUSION}

Rate of psychiatric disorders increased in Egyptian male adolescents in urban areas.

\section{REFERENCES}

1.Atladóttir HO, Parner ET, Schendel $D$, Dalsgaard $\mathrm{S}$, Thomsen $\mathrm{PH}$ and Thorsen $P$ (2012): Time trends in reported diagnoses of childhood neuropsychiatric disorders: a Danish cohort study. Arch Pediatr Adolesc Med: 161(2):193-198. 
2.Biederman J, Faraone SV, Marrs A,

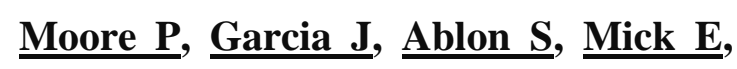
Gershon J and Kearns ME (2017):

Panic disorder and agoraphobia in consecutively referred children and adolescents. J Am Acad. Child Adolescent Psychiatry,36(2):214-23.

3.Bird HR, Gould MS, Yager T, Staghezza B and Canino G (2011): Risk factors for maladjustment in Puerto Rican children. Social Psychiatry \& Psychiatric Epidemiology, 47 (5):783-788.

4.Cecilia A. Essau A, Judith C and Franz P(2013): Frequency and comorbidity of social phobia and social fears in adolescents, Germany: Journal of Behavior Research and Therapy, 37(9):831-843.

5.Diler RS (2013): Panic disorder in children and adolescents, Yonsei Med J, 44(1):174-199.

6.Erskine HE, Baxter AJ and Patton G (2017): The global coverage of prevalence data for mental disorders in children and adolescents, Journal of Behavior Research and Therapy, 402(4): 26-50.

7.Elsabbagh M, Divan $G$ and Koh YJ (2012): Global prevalence of autism and other pervasive developmental disorders. Autism Res., 5(3): 160-179.

8.Hans M, (2010): Childhood stuttering: Incidence and development, Bornholm, Denmark, Archives of General Psychiatry, 69(4):372-380.

\section{Merikangas K, Erin F and Ronald C}

(2010): Epidemiology of mental disorders in children and adolescents, Journal Of American Academy Child Adolescent Pychiatry 38(1): 56-66.
10. Keeton CP, Kolos AC and Walkup

JT (2019): Pediatric generalized anxiety disorder: epidemiology, diagnosis, and management. Division of Child and Adolescent Psychiatry, Johns Hopkins University School of Medicine, Baltimore, Maryland, USA Psychol Violence, 11(3):171-83

11.Kim SJ, Kim BN, Cho SC, Kim JW, Shin MS, Yoo HJ and Kim HW (2010): The prevalence of specific phobia and associated co-morbid features in children and adolescents. Division of Child and Adolescent Psychiatry, Department of Neuropsychiatry, College of Medicine, Seoul National University, 101 Daehakro, Chongno-Gu, Seoul, Korea, 14(4):162-78

12.McGrath JJ, Petersen L, Agerbo E, Mors O, Mortensen PB, and Pedersen CB. A (2014): comprehensive assessment of parental age and psychiatric disorders, JAMA Psychiatry,71(3):301-309.

13.Munezawa T, Kaneita Y, Osaki Y, Kanda H, Ohtsu T, Suzuki H, Minowa M, Suzuki K, Higuchi S, Mori J and Ohida T (2011): Nightmare and sleep paralysis among Japanese adolescents: a nationwide representative survey, Sleep Med., 12(1):56-64

14.Nielsen PR, Benros ME and Dalsgaard S (2016): Associations between autoimmune diseases and attention-deficit/hyperactivity disorder: a nationwide study. Acad Child Adolesc Psychiatry, 56(3):234-240.

15.Ottosen C, Larsen JT and Faraone SV (2019): Sex differences in comorbidity patterns of attention- 


\section{PREVALENCE OF PSYCHIATRIC DISORDERS IN MALE ...}

deficit/hyperactivity disorder. J Am Acad Child Adolesc Psychiatry, 58(4):412-422.

16. Pillai A, Vikam P, Persy C, Robert $A$ and Andrew G. (2018): Nontraditional lifestyles and prevalence of mental disorders in adolescents in Goa, India.The British Journal of Psychiatry, 192: 45-51.

17.Rothman KJ, Greenland S, Lash TL and Modern T (2011): Epidemiology. 3rd ed. Philidelphia, PA: Lippincott Williams \& Wilkins, 73(6):473-481.

18.Pedersen CB, Mors $O$ and Bertelsen A, (2014): A comprehensive nationwide study of the incidence rate and lifetime risk for treated mental disorders. JAMA Psychiatry, 71(5):573-58.

19.Sarkar S, Sinha VK and Praharaj SK (2012): Depressive disorders in school children of suburban India: an epidemiological study

Social Psychiatry \& Psychiatric Epidemiology, 47 (5):783-797.

20.Dubovsky S, (2012): How Common Are Psychiatric Disorders in Adolescents? How Serious? Johns Hopkins University School of Medicine, Baltimore, Maryland, USA, Psychol Violence, 28(3):19-27.

21.Sulttan $S$ and Abdel-Rahman $M$

(2012): Prevalence of ObsessiveCompulsive disorder among female secondary school students in Cairo MD thesis, Faculty of Medicine, Ain Shams University, Cairo, (4)37-49.

22.Sujit S, Vinod K, Manu A and Pushpal D (2016): Prevalence of conduct disorder in school children of Kanke, Department of Child and Adolescent Psychiatry , Psychol Violence, 48(3):159164.

23.Strauz T, Ahalbreg J, Lobbezoo F, Restrepo C, hublin $\mathrm{K}$ and Kononen $\mathrm{M}$ (2010): Awareness of tooth grinding and clenching from adolescence to young adulthood: a nine-year follow-up, Article first published online: 2 MAR 2010 Blackwell Publishing Ltd Journal of Oral Rehabilitation, 37(7):497-500.

24.Wittchen H.U. (2012): Generalized anxiety disorder: prevalence, burden, and cost to society, Journal Of American Academy Child Adolescent Pychiatry 38(1): 56-63.

25. Whiteford HA, Degenhardt $L$ and Rehm J (2010): Global burden of disease attribute to mental and substance disorders: findings from the Global burden of Disease Study, Lancet, (5):382471. 


\section{انتشار الاضطرابات النفسية في المراهقين الأكور في المناطق



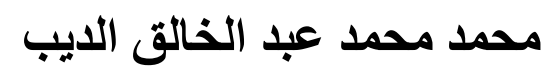 قسم الطب النفسي - بكلية الطب - جامعة الأزهر الخدر Deeb17777@gmail.com}

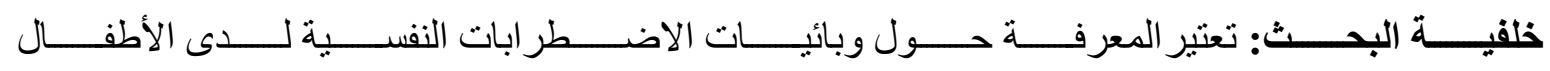

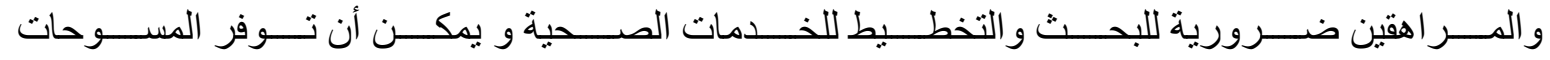

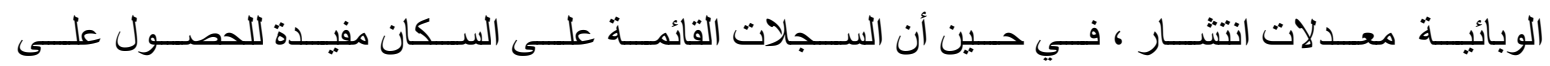
تقدير ات دقيقة لمعدلات الحدوث و والمخاطر.


النفسية ومعدل انتشار ها بين المر اهقين في المناطق الحضرية الحفرية المصرية.

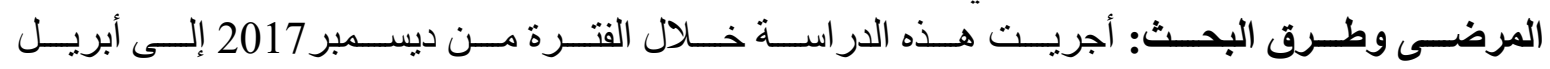

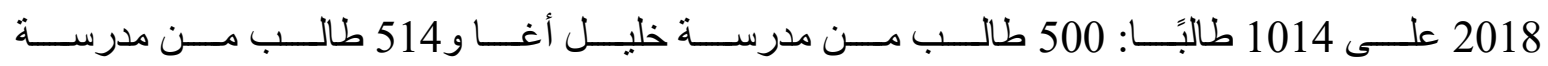

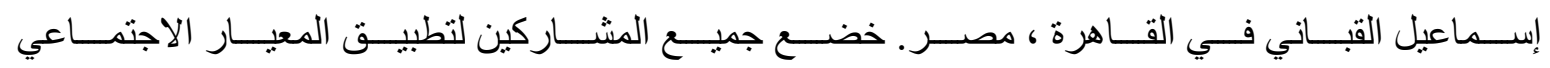



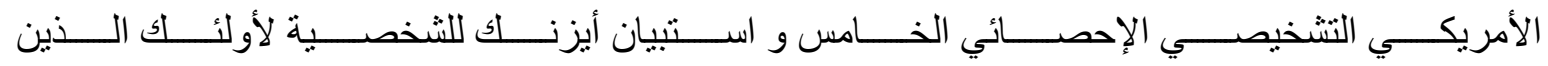

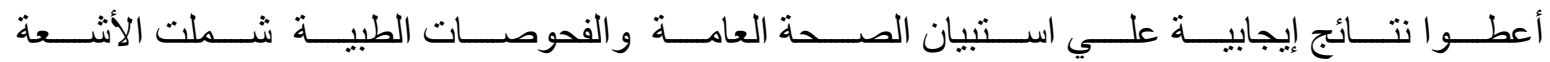

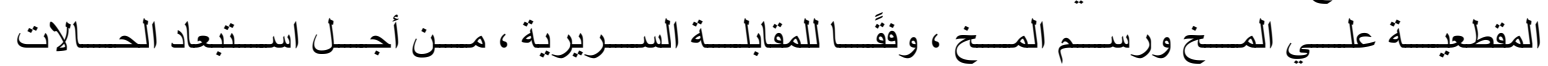
العضوية. نتائج البحث: :

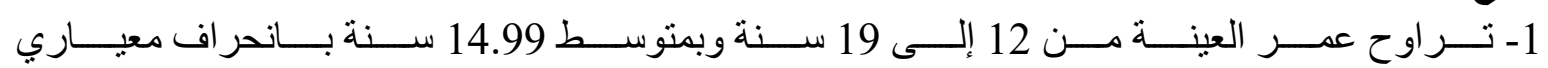
.1 .53

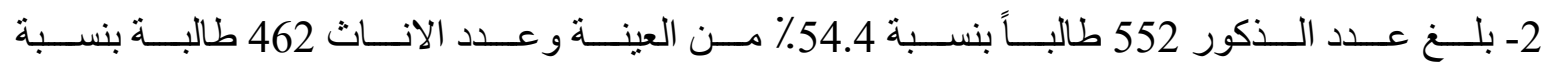
$\% 45.6$

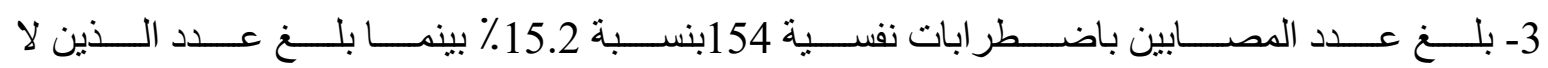



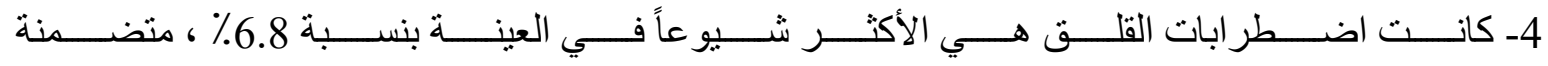



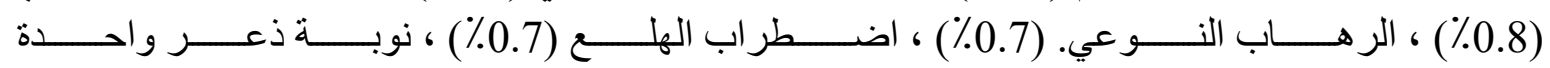

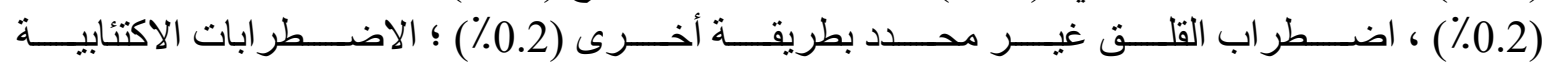

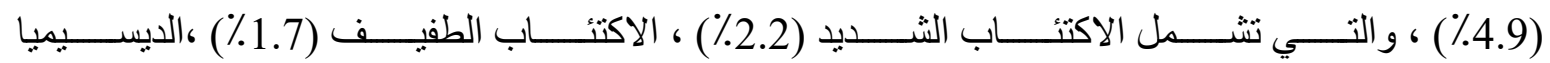

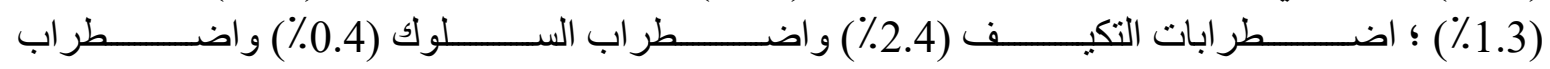
الكو ابيس (0.2\%) و اضطر اب صرير الأسنان (0.2\%). 


\section{PREVALENCE OF PSYCHIATRIC DISORDERS IN MALE ...}

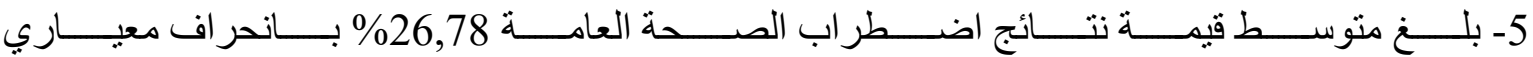

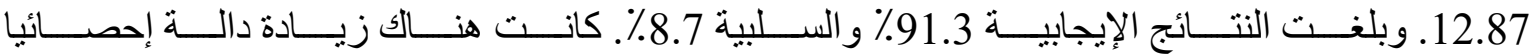

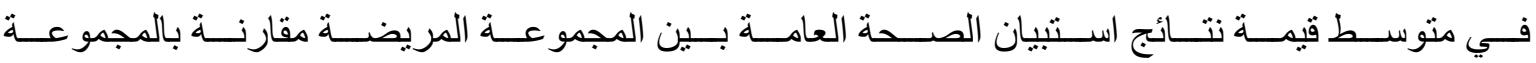
العادية.

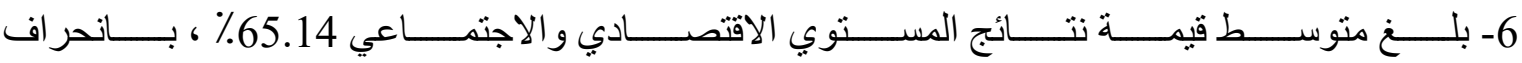
معياري 16.88.

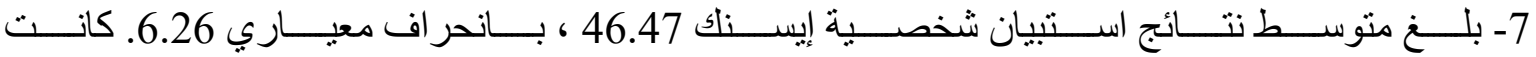

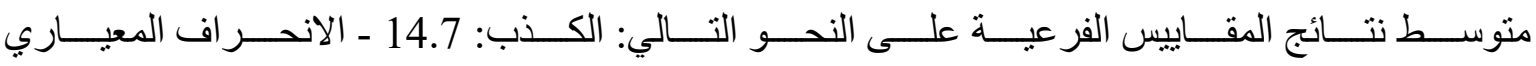

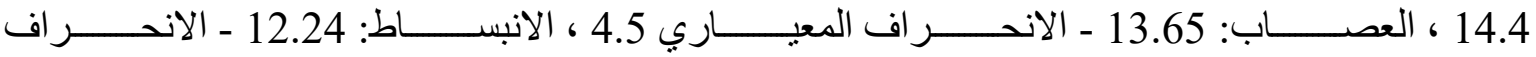



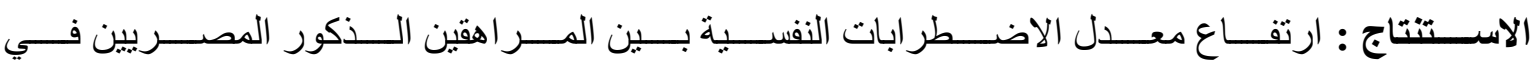
المناطق الحضرية. الكلمات الدالة : الاضطر ابات النفسية ـ المراهقون الذكور - ـ المناطق الحضرية. 